\title{
Formulation optimization and pharmacokinetics of tinidazole crystallo-co-agglomerates
}

\begin{abstract}
The purpose of this research was to obtain directly compressible agglomerates of Tinidazole using a crystallo-co-agglomeration technique and determine its in-vivo performance in rats. Crystallo-co-agglomeration is an extension of the spherical crystallization technique, which enables simultaneous crystallization and agglomeration of 2 or more drugs or crystallization of a drug and its simultaneous agglomeration with another drug or excipient. Tinidazole agglomerates were prepared from Acetone-water-DCM system containing hydroxypropyl methylcellulose (HPMC). Acetone acted as a good solvent for tinidazole, water acted as bad solvent and dichloromethane acted as bridging liquid for agglomeration. The agglomerates were characterized by powder $\mathrm{x}$-ray diffraction (PXRD) which showed that there is decrease in crystallinity or partial amorphization of the drug in its agglomerated form, FTIR which showed that there is no interaction between drug and polymer and were evaluated for tabletting properties. Micromeritic and compressional properties of the agglomerates were affected by incorporated polymer. 23 factorial design was used for optimization wherein the factors were stirring speed, polymer: drug ratio and amount of bridging liquid. The responses evaluated were dissolution, MYP and Carr index. Dissolution of agglomerates increased as compared to pure drug. Also there was an increase in flow property which was indicated by Carr index of drug (40.81) and optimized batch of agglomerates (4.18). In vivo pharmacokinetic studies of tinidazole on rats demonstrated increases in Cmax and AUC of tinidazole crystalloco-agglomerates as compared to that of standard tinidazole and marketed formulation. But there is no significant increase in Tmax may be due to same rate of release.
\end{abstract}

Keywords: tinidazole, crystallo-co-agglomeration, dissolution, flowability, hydroxylpropyl methylcellulose (HPMC)

\author{
Volume 3 Issue 5 - 2017
}

\author{
Trupti D Dongare,' Mangesh R Bhalekar,' \\ Santosh V Gandhi ${ }^{3}$ \\ 'Department of Quality Assurance Techniques, AISSMS College \\ of Pharmacy, India \\ ${ }^{2}$ Department of Pharmaceutics, AISSMS College of Pharmacy, \\ India \\ ${ }^{3}$ Department of Pharmaceutical Chemistry,AISSMS College of \\ Pharmacy, India
}

\begin{abstract}
Correspondence: Santosh V Gandhi, Department of Pharmaceutical Chemistry, AISSMS College of Pharmacy, Keenedy Road, Near RTO, Pune-4I I 00 I, MH, India, Tel +9|-968993218I,Email santoshvgandhi@rediffmail.com
\end{abstract}

Received: June 12, 2017 | Published: August 16, 2017
Abbreviations: SEM, scanning electron microscopy; AUC, the area under curve; PXRD, powder x-ray diffractometry; HPMC, hydroxyl propyl methyl cellulose; FTIR, fourier transform infrared spectroscopy; DCM, dichloromethane; CCA, crystallo-co-agglomeration

\section{Introduction}

In the field of powder technology attempts to design of pharmaceutical substances are undertaken in order to impart various desirable properties, such as enhancement in solubility, obtaining suitable polymorph, improvement in micromeritic and compression properties, and modification of bioavailability. Particle size enlargement has become an important tool in modifying the primary and secondary properties of pharmaceuticals. ${ }^{1,2}$ Spherical crystallization is a nonconventional particle-size enlargement technique which involves crystallization and agglomeration using bridging liquid. Spherical crystallization has been used mainly to obtain directly compressible agglomerates of a single, waterinsoluble large-dose drug, and rarely in combination with a diluent. Most of the excipients, such as diluents and disintegrating agents being hydrophilic cannot be incorporated in the agglomerates using organic bridging liquid thus limiting use of spherical crystallization to obtain agglomerates of low-dose or poorly compressible materials. ${ }^{3-5}$

Kadam et al. ${ }^{6}$ developed the crystallo-co-agglomeration (CCA) technique a modification of the spherical crystallization technique in which a drug is crystallized and agglomerated with an excipient or with another drug, which may or may not be crystallized in the system. ${ }^{6}$ The agglomeration is performed using bridging liquid which is not soluble in good solvent also the difference in the physicochemical properties of the drug molecules and the excipients becomes the major challenge in the selection of a solvent system for the crystallo-co-agglomeration. The present work involves use of CCA technique to obtain the agglomerates of tinidazole to improve its dissolution, compression and flow behavior. The effect of parameters such as stirring speed, polymer: drug ratio and amount of bridging liquid was evaluated. Properties mentioned above was studied using a $2^{3}$ factorial design using desirability function. The process and formula was optimized using 3 factor 2 level design. The In-vivo pharmacokinetic study in wistar rat was done to evaluate in vivo performance of formulated agglomerates.

\section{Materials and methods}

\section{Materials}

Tinidazole was a kind gift from Aristo pharmaceuticals LTD. Daman. Hydroxypropyl methylcellulose (HPMC), Dichloromethane (DCM) (Merck Ltd, Mumbai, India), sodium CMC, acetone, acetonitrile was purchased locally and all chemicals were of analytical grade.

\section{Method}

\section{Crystallo-co-agglomeration ${ }^{7}$}

$0.5 \mathrm{~g}$ of polymeric solution (HPMC) was added in $10 \mathrm{ml}$ of bad solvent (water) 
$1 \mathrm{~g}$ of Tinidazole dissolved in $2 \mathrm{ml}$ good solvent (acetone) $0.5 \mathrm{~g}$ of polymeric solution (HPMC) was added in $10 \mathrm{ml}$ of bad solvent (water)

\section{Addition of bridging liquid}

\section{(DCM) $2 \mathrm{ml}$}

The mixture was stirred using an overhead stirrer for $15 \mathrm{~min}$ at $600 \mathrm{rpm}$ to obtain crystallo-co-agglomerates.

The temperature of the crystallization system was maintained below $5^{\circ} \mathrm{C}$. The stirring was continued to obtain agglomerates, which were then filtered and dried overnight at room temperature.

Selection of optimization model: A three factor two level $2^{3}$ factorial design was selected for optimization wherein the 3 factors were, polymer:

a. Drug ratio (A)

b. Stirring speed (B)

c. Amount of bridging liquid (C)

The responses to be optimized were \% dissolution, Mean yield pressure (MYP) and Carr index (Table 1 and 2). The data obtained was further analysed using Design Expert 10.0 software.

Table I Coded levels translated in actual units

\begin{tabular}{llll}
\hline Coded level & \multicolumn{3}{l}{ Actual value in \% } \\
\cline { 2 - 4 } & A & B & C \\
\hline$-I$ & $0.5: I$ & 400 & $\mathrm{Iml}$ \\
$\mathrm{I}$ & $1.0: \mathrm{I}$ & 600 & $2 \mathrm{ml}$ \\
\hline
\end{tabular}

Table 2 Optimization batches for tinidazole

\begin{tabular}{|c|c|c|c|}
\hline $\begin{array}{l}\text { Formulation } \\
\text { code }\end{array}$ & $\begin{array}{l}\text { Polymer: } \\
\text { drug ratio } \\
\text { (g) A }\end{array}$ & $\begin{array}{l}\text { Stirring } \\
\text { speed rpm } \\
\text { B }\end{array}$ & $\begin{array}{l}\text { Amount } \\
\text { of bridging } \\
\text { liquid (ml) } \\
\text { C }\end{array}$ \\
\hline I & -1 & -1 & -1 \\
\hline 2 & I & -1 & -1 \\
\hline 3 & -1 & I & $-I$ \\
\hline 4 & 1 & I & $-I$ \\
\hline 5 & -1 & -1 & I \\
\hline 6 & 1 & -1 & 1 \\
\hline 7 & -1 & I & I \\
\hline 8 & I & I & I \\
\hline
\end{tabular}

\section{Characterization}

FTIR: FTIR studies were carried out to check whether there are any changes in the pure drug after crystallo-co-agglomeration. FTIR spectra were obtained using a Jasco FTIR (460Plus) spectrometer. The samples of pure drug and physical mixture were prepared into $\mathrm{KBr}$ disks. The scanning range was kept from 4000 to $400 \mathrm{~cm}^{-1}$.

Determination of drug content: Drug content was determined by dissolving samples of optimized batch Crystallo-co-agglomerates of HPMC equivalent to $10 \mathrm{mg}$ of Tinidazole in $10 \mathrm{~mL}$ of acetonitrile. The solution was filtered through Whatman filter paper no. 41, were sui- tably diluted to get a concentration of $10 \mu \mathrm{g} / \mathrm{ml}$. and absorbance was measured at $310 \mathrm{~nm}$ using double beam UV spectrophotometer (Jasco 550 , Japan).

Micromeritic Studies: ${ }^{8-11}$ The flow properties of tinidazole bulk and agglomerates were determined in terms of angle of repose, bulk density, Carr Index and Hausner ratio. Angle of repose was determined by fixed funnel method whereas Carr's Index and Hausnar's ratio were calculated from bulk density and tapped density using methods described in literature. The optimized batch was subjected to porosity determination vis-à-vis tinidazole bulk using Helium Pycnometer (Make: SP Consultants, Model: HP 2000).

In-vitro studies: ${ }^{12}$ The in-vitro studies were conducted in $900 \mathrm{~mL}$ of $0.1 \mathrm{~N} \mathrm{HCl}$ at $100 \mathrm{rpm}$ maintained at $37 \pm 0.5^{\circ} \mathrm{C}$ in a dissolution apparatus (Model TDT-08L, Electrolab) using the basket type. 300mg of drug and agglomerates of HPMC equivalent to $300 \mathrm{mg}$ of drug were added to dissolution medium and the samples were withdrawn at appropriate time intervals. The samples were immediately filtered through $0.45 \mu \mathrm{m}$ membrane filter, suitably diluted and analyzed spectrophotometrically at $310 \mathrm{~nm}$.

Heckel analysis: ${ }^{13}$ Heckel equation is expressed as:

$$
\begin{aligned}
& \ln \left(\frac{1}{1-D}\right)=k P+A \\
& \text { where, } \\
& \mathrm{D}=\text { relative density of a powder compact at pressure } \mathrm{P} \\
& \mathrm{K}=\text { the slope } \\
& \mathrm{P}=\text { pressure }
\end{aligned}
$$

$\mathrm{A}=$ related to the die filling and particle rearrangement before deformation and bonding of the discrete particles which is a function of the initial bulk volume

The Heckel analysis was made using tablets prepared at compaction pressure between 2,4,6,8,10\&12 tonnes in $\mathrm{KBr}$ press using $13.00 \mathrm{~mm}$ flat faces punches for both pure drug and agglomeratesat every pressure applied, the diameter, height, and weight of the tablets were measured. Mean yield pressure (Py) was calculated as the inverse of the slope $(1 / \mathrm{K})$ expressed in tonnes.

Powder $\mathbf{x}$-Ray diffraction (PXRD): ${ }^{14}$ Crystallinity of the drug and optimized batch was determined using Bruker PXRD (Model: D 8 Advance) with copper target. The conditions were: $40 \mathrm{kV}$ voltages; $40 \mathrm{~mA}$ current; at room temperature. The samples were loaded on to the difffractometer and scanned over a range of $2 \theta$ values form 10 to 800 at a scan rate of $0.05 \% \mathrm{~min}$.

Scanning electron microscopy (SEM): The surface morphological properties of Crystallo-co-agglomerates of optimized batch and pure drug was investigated by scanning electron microscopy (SEM - Jeol Instruments, JSM-6360, and Japan). Samples were mounted on a double-faced adhesive tape, sputtered with gold. Scanning electron photographs were taken at an accelerating voltage of $20 \mathrm{kV}$ and obtained micrographs were examined at $\times 100$, magnification.

Animal studies: ${ }^{15,16}$ The rats were fasted for 24 hours with free access to water. Four groups will be made for study and six rats will be taken for each group. The control group will be administered water; the second group got tinidazole suspension in water, third 
group was administered crystallo co agglomerates of drug and fourth group received marketed tinidazole suspension orally using feeding tube. Blood samples were collected from tail vein after capillary anaesthetization at time intervals of 1,2,4,6 hr., $(0.5 \mathrm{ml})$, plasma was immediately separated from blood samples by centrifugation for 10 minutes. Then these plasma samples were analysed by HPLC (UV detector).

Table 3 Animal groups for In-vivo pharmacokinetic study of Tinidazole crystallo-co-agglomerates $(n=6)$

\begin{tabular}{lllll}
\hline Study group & Treatment & Formulation & Dose administered & No of animals \\
\hline Group I & Control & Vehicle & -- & 6 \\
Group 2 & Standard I & Tinidazole Drug Powder & $50 \mathrm{mg} / \mathrm{kg}$ & 6 \\
Group 3 & Test I & Crystallo-Co-Agglomerates of Drugs & $50 \mathrm{mg} / \mathrm{kg}$ & 6 \\
Group 4 & Test 2 & Marketed Formulation of the Drug (Tiniba 300mg) & $50 \mathrm{mg} / \mathrm{kg}$ & 6 \\
\hline
\end{tabular}

\section{Result and discussion}

\section{Preparation of crystallo-co-agglomerates}

Tinidazole is an antiprotozoal which is a BCS Class II drug poorly water soluble and processes poor compaction and flow properties. The agglomerates of tinidazole were prepared using a crystallo-coagglomeration technique. Tinidazole was crystallized from acetonewater-DCM system and agglomerated with hydrophilic polymer HPMC. Tinidazole is freely soluble in acetone, but practically insoluble in water. Also it is soluble in DCM (bridging liquid) which is immiscible with water. Hence, these solvent systems were selected for the present study. In this process, crystallization of drug was performed by the addition of the anti-solvent phase (water) to drug solution. The addition of bridging liquid (DCM) promotes the formation of liquid bridges between the drug crystals to form crystallo-co-agglomerates. The agglomerated crystals are formed by coalescence of these dispersed crystals. The effect of different variables on formulation of agglomerates of tinidazole was studies with help of a three factor two level design (Table 4). The response variables chosen were MYP which indicated compression behavior, dissolution at end of $2 \mathrm{hrs}$ and Carr index to predict changes in flow behavior.

\section{Infrared spectroscopy (FTIR)}

FTIR spectra of pure drug and crystallo-co-agglomerate were shown in (Figure 1A). FTIR studies were carried out to check whether there are any changes in the pure drug after crystallo-coagglomeration. The major peaks of Tinidazole are observed at:

$603.61,678.82,742.46,786.815,885.166,981.59,1038.48,1063.55$ $, 1125.26,1265.07,1367.28,1522.52,1558.2,1698.02,1760.69,1908.2$ $2,2088.53,2241.84,2334.41,2359.48,2407.69,2528.22,2782.78,2884$ $.99,2912.95,2999.73,3129.9 \mathrm{~cm}^{-1}$. Upon comparison between FTIR spectra of pure drug and crystallo-co-agglomerate all the characteristic peaks were retained which indicate absence of significant interaction between the excipients used in process with tinidazole.

\section{Micromeritic properties}

Micromertic properties of the crystallo co agglomerates were studied in terms of bulk density, tapped density, Carr index, Hausner ratio and angle of repose. Tinidazole bulk had a significantly higher angle of repose (360) which may be due to irregular shape of the crystals whereas that of crystallo-co-agglomerates was seen to have angle of repose between (15.00-30.01) (Table 4). The Carr index
Chromatographic conditions: The system used for the study was HPLC (UV detector). Column used for the separation is Nucleosil E7060354 and the mobile phase used for the optimization is CAN: BUFFER $(10 \mathrm{Mm})=80: 20$ at flow rate $1 \mathrm{ml} / \mathrm{min}$. The detection wavelength is $310 \mathrm{~nm}$. The capacity of loop of sample injector is $50 \mu 1$. Temperature of column in ambient (Table 3). and Hausner ratio of agglomerates ranged between (4.18-17.2) and $(1.04-1.20)$ respectively compared to that of bulk tinidazole (40.81\% and 1.68). This indicates improvement in the flowability of the agglomerated crystals. The reason for the improved flow of agglomerates is the significant reduction in the interparticle friction because of reduced contact area and the larger size of the crystals (Figure 1B).

\section{Porosity determination of optimized batch}

The bulk volume of $1.0 \mathrm{gm}$ sample of Tinidazole and its Crystalloco-agglomerates both was $1.9 \mathrm{cc}$, while the true volume obtained by Helium Pycnometry was 1.7 and $1.2 \mathrm{cc}$, respectively leading to porosity of 0.1052 and 0.3684 , respectively. This shows higher surface area of agglomerates over bulk Tinidazole which is by virtue of higher porosity.

\section{Determination of drug content}

Drug contents in Crystallo-co-agglomerates of optimized batch was found to be between $98.0-100.5 \%$

\section{Heckel analysis}

Heckel analysis has been used to classify powders as their compaction behaviour and for the interpretation of the mechanism of bonding. Mean yield pressure (Py) is the pressure required to deform a powder or granules and to obtain compacts and is defined as the inverse of slope of the linear portion of the Heckel plot. The slope (k) is an indication of the deformation behaviour of the material. With low values of Py, the amount of plastic deformation increases and when high values of Py is an indication of the material compressing behaviour is mainly fragmentation. The values obtained from Heckel equation as shown in Table 4 indicated significant low mean yield pressure (Py) of crystallo-co-agglomerates (1.5-3.99ton) than plain tinidazole (5.73tonns) indicating improvement in compaction behaviour of crystallo-co-agglomerate.

\section{In-vitro studies}

In In-vitro dissolution study of crystallo-co-agglomerates showed significantly faster drug release profile $(93.81 \%)$ as compared with plain tinidazole $(36.00 \%)$ in $2 \mathrm{hrs}$. The reason for this faster drug dissolution was linked to the increase in surface area, wetting tinidazole agglomerates, showed better wettability due to addition of hydrophilic polymer and the porous internal structure resulted in faster dissolution. 
Table 4 Trial runs for optimization of tinidazole agglomerates and the response variables

\begin{tabular}{|c|c|c|c|c|c|c|c|c|}
\hline $\begin{array}{l}\text { Formulation } \\
\text { code }\end{array}$ & $\begin{array}{l}\text { Polymer: } \\
\text { drug ratio (g) } \\
\text { (A) }\end{array}$ & $\begin{array}{l}\text { Stirring } \\
\text { speed (rpm) } \\
\text { (B) }\end{array}$ & $\begin{array}{l}\text { Amount } \\
\text { of bridging } \\
\text { liquid(ml) (c) }\end{array}$ & $\begin{array}{l}\text { Hausner } \\
\text { ratio }\end{array}$ & $\begin{array}{l}\text { Carr } \\
\text { index } \\
(\%)\end{array}$ & $\begin{array}{l}\text { Angle of } \\
\text { repose }\left(\theta^{\circ}\right)\end{array}$ & $\begin{array}{l}\text { Myp } \\
\text { (Tonnes) }\end{array}$ & $\begin{array}{l}\% \text { Release } \\
\text { of } \\
\text { tinidazole }\end{array}$ \\
\hline I & $0.5: 1$ & 400 & I & 1.05 & 5.04 & 17 & 2.295 & 89.35 \\
\hline 2 & I.0:I & 400 & I & I.II & 10.5 & 26 & 3.26 & 90 \\
\hline 3 & $0.5: 1$ & 600 & I & 1.05 & 4.99 & 15.19 & 1.5 & 92.3 \\
\hline 4 & I.0:I & 600 & I & 1.06 & 6.26 & 20 & 2.421 & 87.56 \\
\hline 5 & $0.5: 1$ & 400 & 2 & 1.08 & 8 & 22 & 2.512 & 85.55 \\
\hline 6 & I.0:I & 400 & 2 & 1.2 & 17.2 & 30.01 & 3.99 & 76.21 \\
\hline 7 & $0.5: 1$ & 600 & 2 & 1.04 & 4.18 & 15 & 1.6 & 93.81 \\
\hline 8 & I.0:I & 600 & 2 & I.I & 9.75 & 24 & 3.11 & 80 \\
\hline Tinidazole & - & - & - & 1.68 & 40.81 & 36 & 5.73 & 36 \\
\hline
\end{tabular}
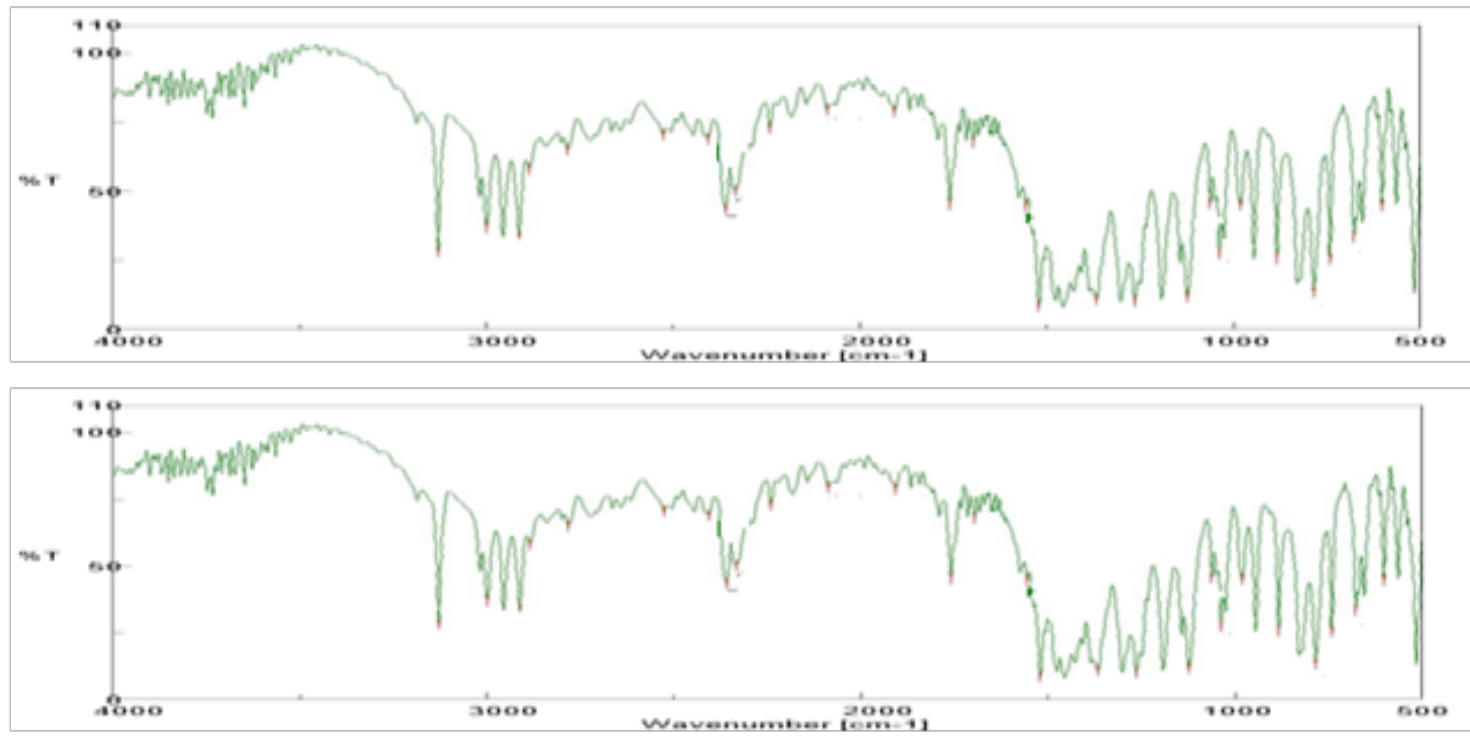

Figure I FTIR Spectra of Tinidazole and Agglomerates of Tinidazole.

(A):Tinidazole (Pure drug) (B): Crystallo-co-agglomerates of optimized batch of tinidazole

\section{Optimisation}

The results of optimization runs were analysed using Design Expert 10.0 software.

$$
\begin{array}{cc}
\text { Equation } & \text { for } \\
1.500 \mathrm{AB}+0.14 \mathrm{AC}-0.020 \mathrm{BC}
\end{array} \quad \mathrm{MyP}=+2.59+0.61 \mathrm{~A}-0.43 \mathrm{~B}+0.22 \mathrm{C}-
$$

The mean yield pressure values of cystallo-co-agglomerates were found to be higher at high polymer and high bridging liquid concentration, whereas at low values of polymer the increase in bridging liquid reduced MYP sharply which may be due to porous agglomerates whereas HPMC being soft and plastic in nature gives better compressibility to the formed agglomerates as it undergoes plastic deformation. The stirring speed did not have appreciable effect on MYP hence was excluded from equation. The combination of low bridging liquid and high stirring speed reduced the MYP as the particle collisions increase at high speed which resulted in smaller particle size and smaller MYP (Figure 2).

\section{Equation for carrs index}

Carrs index
$0.87 \mathrm{BC}$

Carr index was reduced by decreasing the polymer and increased to some extent by stirring speed. The bridging liquid had highest influence on increasing the Carr index, Optimum Carr index values $(4.18-17.2 \%)$ were seen at high stirring speeds and bridging liquid combination, the values declined with decrease in either of the variables. Whereas low polymer and high bridging liquid combinations exhibited good Carr index (Figure 3). Equation for \% release of Tinidazole $=+86.85-3.40 \mathrm{~A}+1.57 \mathrm{~B}-2.96 \mathrm{C}-1.23 \mathrm{AB}-2.38 \mathrm{AC}+1.44 \mathrm{BC}$

The \% drug release is most coveted characteristic of a drug material; dissolution of Tinidazole was highly reduced by increasing polymer content as agglomerates formed were sticky in nature. The low stirring speeds which produce bigger agglomerates may also reduce the dissolution. The higher polymer: drug ratio and low 
bridging lead to significant reduction in dissolution. High bridging liquid and high stirring speed show increase in dissolution. Also a combination of low polymer: drug ratio and high stirring speed lead to increase in dissolution (Figure 4). Incorporation of HPMC causes faster consolidation and yields particles with lower tortuosity and hence batches containing HPMC at higher levels exhibit slower release of drugs.

\section{PXRD}

The PXRD scan of plain Tinidazole showed intense peaks of crystallinity, whereas the PXRD pattern of agglomerates exhibited halo pattern with less intense and denser peaks compared with plain tinidazole indicating Figure 5 the decrease in crystallinity or partial amorphization of the drug in its agglomerated form. ${ }^{17}$

\section{SEM}

The tinidazole in Figure 6A particles in the physical mixture were irregular and the shape of prepared agglomerates Figure 6B is uniform. The agglomerates show smoother surface and larger size which contribute to better flow.
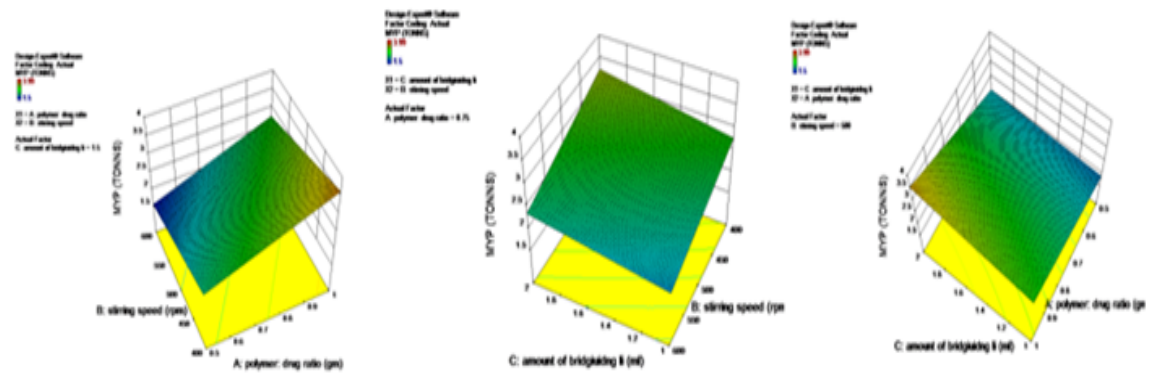

Figure 2 3D Surface plots for MYP.
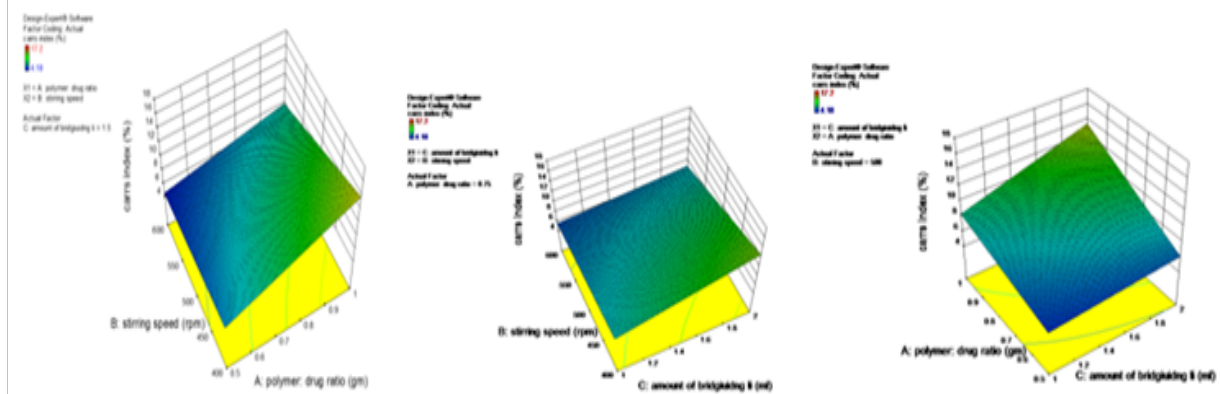

Figure 3 3D Surface plot for Carr Index
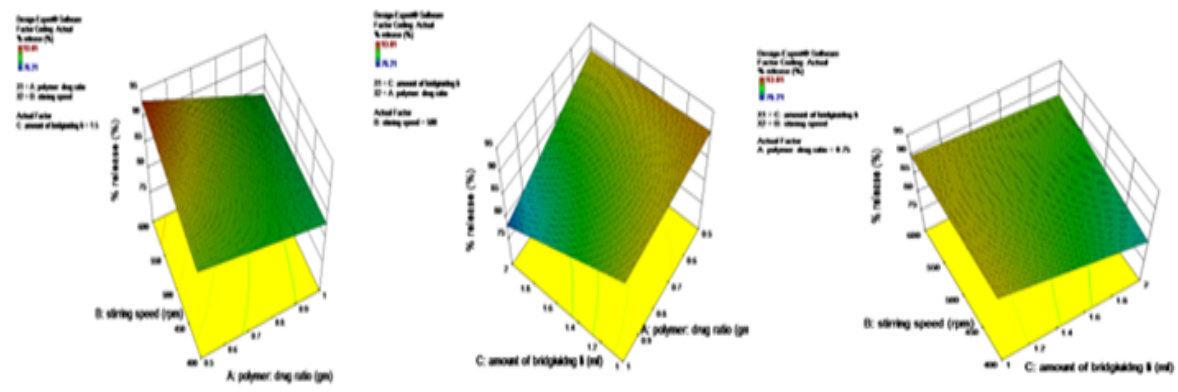

Figure 4 3D Surface plot for $\%$ release of drug.

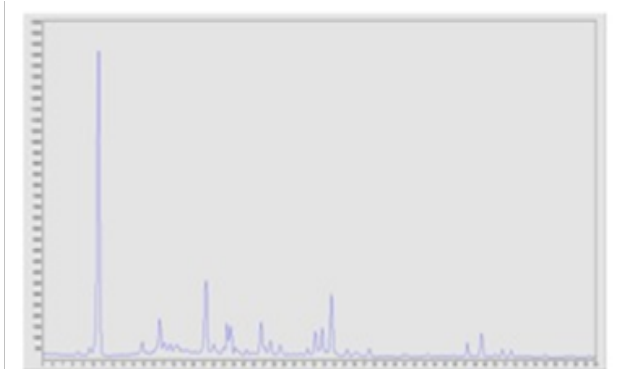

A

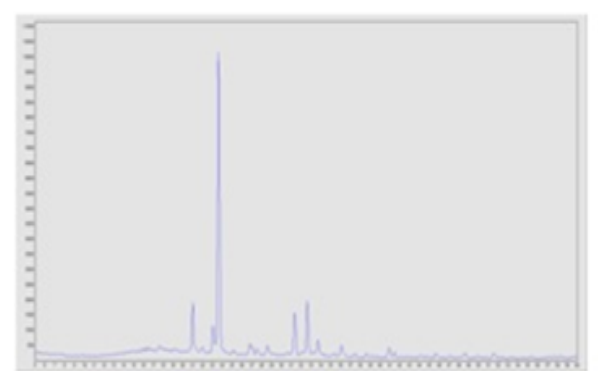

B

Figure 5 PXRD Graphs of A: Bulk Tinidazole B:Agglomerates of Tinidazole. 


\section{Animal studies}

Under the chromatographic conditions described, tinidazole peaks were well observed. The average retention time of tinidazole was $3.05 \mathrm{~min}$. The standard calibration curve for the determination of tinidazole in mobile phase was linear over the range of $0.1-50 \mathrm{mcg} / \mathrm{ml}$. the linearity equation and correlation coefficient $\left(\mathrm{r}^{2}\right)$ for calibration curve were found to be $\mathrm{y}=11518 \mathrm{x}+10839, \mathrm{r}^{2}=0.995$., respectively (Figure 7) (Table 5 and 6). The $\mathrm{C}_{\max }$ of crystallo-co-agglomerates was higher compared to standard (API) and marketed formulation but there is no significant increase in $\mathrm{T}_{\max }$ may be due to same rate of release. AUC of crystallo-co-agglomerates is also higher as compared to standard (API) and marketed Tinidazole (Figure 8) (Table 7).

Table 5 Area by HPLC method after blood withdrawal at different time interval in wistar rats

\begin{tabular}{lllll}
$\begin{array}{l}\text { Time } \\
\text { (hr) }\end{array}$ & Control & API & Markated & $\begin{array}{l}\text { Crystallo-co- } \\
\text { agglomerates }\end{array}$ \\
$1 / 2$ & - & 1081363.8 & 1682650.65 & 2601393.5 \\
1 & - & 683240 & 994110.25 & 1843726.43 \\
2 & - & 549913 & 647331.39 & 711562.9 \\
4 & - & 148731.483 & 227769.703 & 320376.603 \\
6 & - & 112092.8 & 124864 & 130185 \\
\hline
\end{tabular}

Table 6 Maximum concentration after different interval of time of API ( Tinidazole), Marketed, Crystallo-co-agglomerates (CCA)

\begin{tabular}{llll}
\hline $\begin{array}{l}\text { Time } \\
(\mathrm{Hrs})\end{array}$ & $\begin{array}{l}\text { API } \\
(\text { Tinidazole }) \\
(\mu \mathrm{g} / \mathrm{ml})\end{array}$ & $\begin{array}{l}\text { Marketed } \\
(\mu \mathrm{g} / \mathrm{ml})\end{array}$ & $\begin{array}{l}\text { Crystallo-co- } \\
\text { agglomerates(CCA) } \\
(\mu \mathrm{g} / \mathrm{ml})\end{array}$ \\
\hline 0 & - & - & - \\
$1 / 2$ & 8.44714 & 13.66742 & 21.6438 \\
1 & 4.990698 & 7.689625 & 15.06586 \\
2 & 3.833174 & 4.678945 & 5.236593 \\
4 & 0.350179 & 1.036376 & 1.840375 \\
6 & 0.032087 & 0.142965 & 0.189161 \\
\hline
\end{tabular}

Table 7 In-vivo pharmacokinetic parameters of standard (API), marketed and Tinidazole crystallo-co-agglomerates (CCA) in rats

\begin{tabular}{llll}
\hline Parameters & $\begin{array}{l}\text { Tinidazole } \\
\text { (API) }\end{array}$ & $\begin{array}{l}\text { Tinidazole } \\
\text { CCA }\end{array}$ & $\begin{array}{l}\text { Marketed } \\
\text { formulation }\end{array}$ \\
\hline $\mathrm{C}_{\max }(\mu \mathrm{g} / \mathrm{ml})$ & $8.447 \mathrm{l}$ & 21.6438 & 13.6674 \\
$\begin{array}{l}\mathrm{AUCo}-\mathrm{t}(\mu \mathrm{g} / \\
\mathrm{ml} / \mathrm{hr})\end{array}$ & 14.2149 & 33.8445 & 21.8349 \\
\hline
\end{tabular}
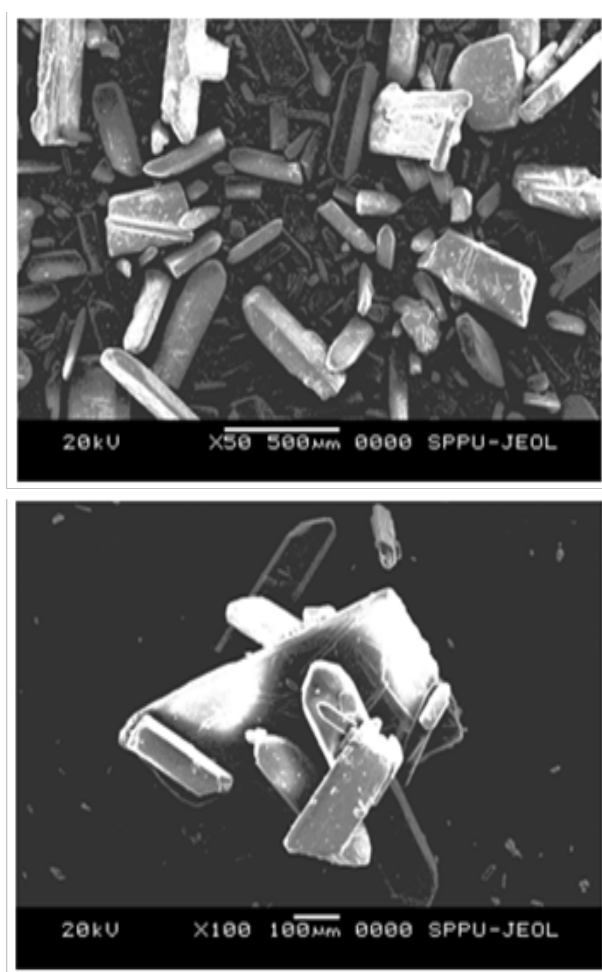

Figure 6 Photomicrograph (40X); (A): Bulk tinidazole (B):Agglomerates of tinidazole

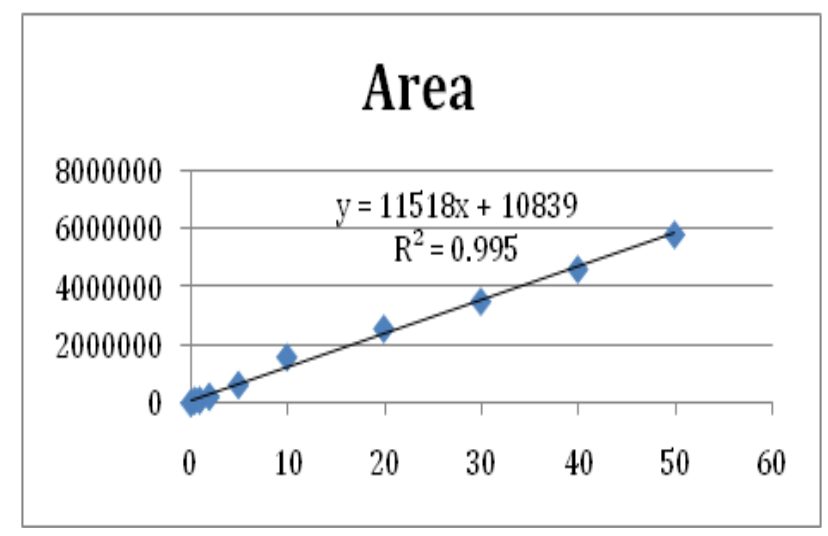

Figure 7 Calibration curve of Tinidazole in human plasma.

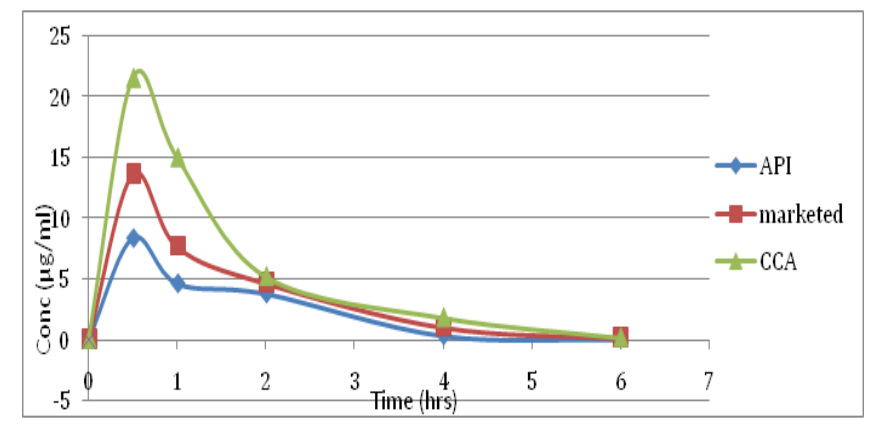

Figure 8 In-vivo plasma concentrations profile of Tinidazole (API),Tinidazole marketed (marketed), Tinidazole crystallo-co-agglomerates (CCA), in rats $(n=6)$. 


\section{Conclusion}

The crystallo-co-agglomeration process was optimized with respect to the variables such as stirring speed, polymer drug ratio and bridging liquid. It was seen dissolution increases with polymer content, decreases with stirring speed, and increases with bridging liquid. The required Carr index could be achieved at lower polymer, high speed and low bridging liquid. The MYP was increased the most by polymer, bridging liquid and decreased with rotation speed. In vivo pharmacokinetic studies of tinidazole on rats demonstrated increases in $\mathrm{C}_{\max }$ and $\mathrm{AUC}$ of tinidazole crystallo-co-agglomerates as compared to that of standard tinidazole and marketed formulation. But there is no significant increase in $\mathrm{T}_{\text {max }}$ may be due to same rate of release.

\section{Acknowledgements}

Authors are thankful to the principal, AISSMS College of pharmacy for providing necessary facilities to carry out the experiment. Authors are also thankful to Aristo pharmaceuticals LTD. Daman for drug samples and Savitribai Phule Pune University for PXRD SEM studies.

\section{Conflict of interest}

The author declares no conflict of interest.

\section{References}

1. Pawar AP, Paradkar AR, Kadam SS, et al. Crystallo-co-agglomeration a novel technique to obtain ibuprofen-paracetamol agglomerates. AAPS Pharm Sci Tech. 2004;5(3):e44.

2. Jadhav N, Pawar A, Paradkar A. Design and evaluation of deformable talc agglomerates prepared by crystallo-co-agglomeration technique for generating heterogeneous matrix. AAPS Pharm Sci Tech. 2007;8(3):E59.

3. Sarfaraz Md, Arshad Ahmed Khan K, Doddayya H, et al. Particle Design of aceclofenac-disintegrant agglomerates for direct a compression by crystallo-co-agglomeration technique. Asian J Pharm Tech. $2011 ; 1(2): 40-48$.
4. Pawar A, Paradkar A, Kadam S, et al. Agglomeration of Ibuprofen with talc by novel crystallo-co-agglomeration technique. AAPS PharmSciTech. 2004;5(4):e55.

5. Anant P, Atmaram P. Crystallo-co-agglomeration: a novel particle engineering technique. Asian Journal of Pharmaceutics. 2010;4 (1):4-10.

6. Kadam SS, Mahadik KR, Paradkar AR, et al. A process for making agglomerates for use as or in a drug delivery system. Indian patent, India; 1997. $183036 \mathrm{p}$.

7. Nikita R, Mitali B, Priyanka D Crystallo-co-agglomeration: a novel technique to improve flow and compressibility. Journal of Drug Delivery \& Therapeutics. 2013;3(4):178-183.

8. Leon Lachman, Herbert Lieberman. The theory and practice of industrial pharmacy. 3rd ed. New Delhi: CBS Publishers and distributors; 2009.

9. Aulton ME. Aulton's Pharmaceutics the design and manufacturing of medicines. 3rd ed. New York, USA; 2007.

10. Subrahmanyam CVS. Textbook of Physical Pharmaceutics. 2nd ed. Vallabh Prakashan, Delhi, India; 2000. p. 221-227.

11. Hari Krishna E, V Rama Mohan G, Jyothi S. Spherical crystallisation a modern technique for direct compression of pharmaceutical substances. Asian Journal of Pharmaceutical and Clinical Research. 2012;5(Suppl 4):114-117.

12. Sabitha P, Sujani S, Ravindra K. Microcrystals: for improvement of solubility and dissolution of Tinidazole. Asian J Pharm Tech. 2011;1(3):64-69.

13. Pradnya P, VRM G, Udupi RH, et al. Spherical agglomeration-direct tableting technique. IRJP. 2011;2:30-35.

14. Yadhav A, Yadhav V. Directly compressible roxithromycin recrystallised agglomerates by solvent change method. Der Pharmacia Lett. 2010;2(1):25-40.

15. Merck index. 15th ed. p. 9609-9610.

16. Alton KB, Patrick JE. High-performance liquid chromatographic assay for the antiprotozoal agent, Tinidazole, in human plasma. J Pharm Sci. 1979;68(5):599-601. 